\title{
Cytotoxic, Antioxidant and Antimicrobial Properties of Red Sweet Pepper (Capsicum Annuum L. var. Llanerón) Extracts: In Vitro Study
}

\author{
Rosa Raybaudi-Massilia ${ }^{a^{*}}$, Alírica I. Suárez ${ }^{\mathrm{b}}$, Francisco Arvelo ${ }^{\mathrm{c}, \mathrm{d}}$, Alexandra \\ Zambrano $^{\mathrm{a}}$, Felipe Sojo ${ }^{\mathrm{c}, \mathrm{d}}$, María I. Calderón-Gabaldón ${ }^{\mathrm{a}}$, And Jonathan \\ MOSQUEDA-MELGAR ${ }^{a}$ \\ ${ }^{\text {a }}$ Institute of Food Science and Technology, Faculty of Science, Central University of Venezuela, \\ Caracas-Venezuela. Postal code 1041-A, Postal zip 47097 \\ b Laboratory of Natural Products, Faculty of Pharmacy, University Central of Venezuela, Caracas-Venezuela \\ ${ }^{c}$ Foundation Institute for Advanced Studies-IDEA, Caracas-Venezuela \\ ${ }^{\mathrm{d}}$ Institute of Experimental Biology, Faculty of Science, Central University of Venezuela, Caracas-Venezuela \\ ${ }^{*}$ Corresponding author \\ rosa.raybaudi@ciens.ucv.ve \\ TEL: +58 212-7534403 \\ FAX: $+58212-7533871$
}

Received: 3 January 2017; Published online: 18 October 2017

\begin{abstract}
Alcoholic and aqueous extracts were obtained from red sweet pepper (Capsicum annuum L.) by different methodologies to evaluate their cytotoxic, antioxidant and antimicrobial properties. Alcoholic extracts (MFP, MSd, SFP, SDP, SSd) from fresh red sweet pepper (FP) and dry pulp (DP) and seed (Sd) were obtained by maceration $(\mathrm{M})$ and Soxhlet $(\mathrm{S})$ equipment using methanol as extraction solvent; whereas aqueous extracts (LFP, LSd) were obtained by decoction followed by lyophilization (L). Human tumoral cell lines from breast (MCF-7 and SKBr3), prostate (PC3) and cervix (HeLa), and fibroblasts (as control) were used to determine the cytotoxic properties by the MTT assay. Antioxidant and antimicrobial properties were determined by DPPH and disc diffusion method, respectively. The extracts SDP and SFP showed the higher cytotoxic activity. The SDP extract had a significant $(\mathrm{P}<$ $0.05)$ in-vitro effect on HeLa $(1.9 \pm 1.4 \mu \mathrm{g} / \mathrm{mL})$ and PC3 $(<1 \mu \mathrm{g} / \mathrm{mL})$ cells with a moderated impact on fibroblasts $(26.1 \pm 1.2 \mu \mathrm{g} / \mathrm{mL})$; whereas, SFP had a significant $(\mathrm{p}<0.05)$ effect on MCF-7 cell line $(2.1$ $\pm 1.2 \mu \mathrm{g} / \mathrm{mL})$ with a moderated impact on fibroblasts $(25.9 \pm 1.0 \mu \mathrm{g} / \mathrm{mL})$. The higher antioxidant activity was found for MFP $(80.3 \pm 0.2 \%)$ and SFP extracts $(75.5 \pm 0.5 \%)$. Mild antimicrobial activity was only observed for alcoholic extracts. The results showed the potential of red sweet pepper (C. annuum L.) as a source of antioxidant and cytotoxic compounds, and suggest the need of further studies to isolate and characterize the bioactive compounds that impart those properties.
\end{abstract}

Keywords: Cytotoxic; Antioxidant; Antimicrobial; Capsicum annuum L.; Red sweet pepper

\section{Introduction}

Fruits and vegetables have been recognized as natural sources of various bioactive compounds, the main phytochemical compounds present in these products being the flavonoids, anthocyanins, vitamins $\mathrm{C}$ and $\mathrm{E}$, phenolic compounds, dietary fibre, and carotenoids (Gonzalez-Aguilar et al., 2008). These phytochemical compounds have demonstrated that they can decrease the 
risk of developing various chronic diseases due to their antioxidant and radical-scavenging activities (Ayala-Zavala et al., 2011).

Peppers are usually consumed as food and used as additives in the food industry. They have a significant role in traditional medicine: in fact, in Indian, Native American, and Chinese traditional medicine, Capsicum species have been used for the treatment of arthritis, rheumatism, stomach aches, skin rashes, dog/snake bites, and flesh wounds. These therapeutic applications are related to the capsaicinoids, phenolic compounds, and carotenoids content of the peppers (Hernandez-Ortega et al., 2012).

Different varieties of Capsicum annuum $\mathrm{L}$. have been studied and have shown benefit with respect to some disorders, mainly for those related to mental health. Yazdizadeh Shotorban, Jamei, and Heidari (2012)), in studies performed with rats, established the antioxidant activity of bell pepper, which showed a protective effect on the brain cells. In the same way, Oboh and Rocha (2008) reported that chemical compounds present in unripe hot pepper inhibited lipid peroxidation in rat brain, thus enhancing the protective properties on the brain cells.

Sweet pepper $(C$. annuum L.) is a plant whose fruits have different forms and size, and several colours, ranging from yellow to red, from intense purple to dark green to black, depending on the genotype or the seasonal period of breeding (Nazzaro et al., 2009). This fresh fruit is known as an excellent source of Vitamin $\mathrm{C}$ and $\mathrm{E}$ as well as provitamin A, carotenoids and polyphenols, and are considered of great importance because of their antioxidant properties (Nazzaro et al., 2009; Shaha, Rahman, \& Asrul, 2013; Yazdizadeh Shotorban et al., 2012).

The main objective of this research was to evaluate the In vitro cytotoxic properties of aqueous and alcoholic extracts of pulp and seed of red sweet pepper (C. annuum L.) on human tumoral cells of breast, prostate and cervix, in addition to the study of the antioxidant (by DPPH method), and antimicrobial (against Salmonella enterica ser. Enteritidis, Staphylococcus aureus and Listeria monocytogenes) properties of those extracts.

\section{Materials and Methods}

\section{$2.1 \quad$ Vegetable}

Red sweet pepper (Capsicum annuum L. var Llanerón) commonly called in Venezuela "Ají dulce Llanerón" is a cultivated variety in the Venezuelan plains, specifically in the Guárico state, and is characterized by having an elongated shape, orange or red colour when ripening and with intense flavour. Red sweet pepper was harvested in summer (March to August) and supplied commercially to Caracas city. They were selected in a local supermarket (Caracas, Venezuela) at commercial ripeness and maintained at $7{ }^{\circ} \mathrm{C}$ until processing.

\section{$2.2 \quad$ Preparation of Red sweet pepper seeds and pulp methanolic extracts by Soxhlet apparatus}

Samples of the seed and pulp, from red sweet pepper $(300 \mathrm{~g})$ were dried at room temperature $\left(25-27{ }^{\circ} \mathrm{C}\right)$ and then finely ground with a ceramic mortar, and submitted to an extraction process (individually) with methanol, analytic grade (99.8\%) (J.T. Baker, Phillispsburg, NJ) in Soxhlet apparatus for 12 hours at a ratio of 1:2 (vegetable sample: methanol) (at solvent boiling temperature of approx. $50{ }^{\circ} \mathrm{C}$ ) as was suggested by Leong, Alviarez, Compagnone, and Suarez (2009). Then, the mixtures were vacuum filtered (paper Whatman $\mathrm{N}^{\circ} 1$ ). The solvent was removed in vacuo using a rotator evaporator at $45-50{ }^{\circ} \mathrm{C}$ for $60 \mathrm{~min}$. approximately or until dryness in order to obtain the sweet pepper raw extracts from fresh pulp (FP), dried pulp (DP) and seed (Sd).

\subsection{Preparation of Red sweet pepper seeds and pulp methanolic extracts by maceration}

Samples of the seed and pulp, from red sweet pepper $(200 \mathrm{~g})$ were dried at room temperature $\left(25-27{ }^{\circ} \mathrm{C}\right)$ and then finely ground with a ceramic mortar and submitted to maceration using 
methanol, analytic grade (99.8\%) (J.T. Baker, Phillispsburg, NJ) for 7 days at a ratio of 1:2 (vegetable sample: methanol) at room temperature $\left(25-27^{\circ} \mathrm{C}\right)$ as suggested by Chavez et al. (2013). Then, the mixtures were vacuum filtered (paper Whatman $\mathrm{N}^{\circ} 1$ ). The solvent was removed in vacuo using a rotator evaporator at $45-50{ }^{\circ} \mathrm{C}$ for $60 \mathrm{~min}$. approximately or until dryness to obtain the raw extract of sweet pepper fresh pulp (MFP) and sweet pepper seed (MSd) macerated.

\subsection{Preparation of Red sweet pepper aqueous extract by decoction}

The aqueous extracts of red sweet pepper seed and pulp were obtained by decoction according to methodology used by Suarez et al. (2006). For these, $500 \mathrm{~g}$ of the seed or pulp were boiled in 500 $\mathrm{mL}$ of distilled water for 30 minutes. The decoction was then vacuum filtered, and the aqueous extracts were stored in glass vials, and frozen for subsequent lyophilization to produce powdered forms of sweet pepper fresh pulp extract (LFP) and sweet pepper seed extract (LSd) lyophilized.

\subsection{Human tumoral cell lines}

Human tumoral cells from MCF-7 (breast carcinoma, without overexpression of the HER2/cerb-2 gene), SKBR3 (breast carcinoma, in which the HER2/c-erb-2 gene is overexpressed), PC3 (prostate carcinoma) and HeLa (cervical epithelial carcinoma) were used to determine the cytotoxic activity from Red sweet pepper seed and pulp extracts. Human breast cancer cell lines were grown in Dulbecco's modified Eagle's medium (DMEM; Gibco, USA) supplemented with $10 \%(\mathrm{v} / \mathrm{v})$ heat inactivated fetal bovine serum (FBS; Gibco), $2 \mathrm{mM}$ glutamax (Gibco), 100 units/ml penicillin (Gibco) and 100 $\mu \mathrm{g} / \mathrm{ml}$ streptomycin (Gibco). Prostate carcinoma (PC3) and cervical epithelial carcinoma (HeLa) were grown in Roswell Park Memorial Institute medium (RPMI 1640; Gibco) supplemented with $10 \%$ (v/v) heat inactivated FBS, 2 $\mathrm{mM}$ glutamax, 100 units $/ \mathrm{ml}$ penicillin and 100 $\mu \mathrm{g} / \mathrm{ml}$ streptomycin. Human dermis fibroblast, used as control cells, were obtained from primary culture and grown in DMEM medium supplemented with $10 \%(\mathrm{v} / \mathrm{v})$ heat inactivated FBS, $2 \mathrm{mM}$ glutamax, 100 units/ml penicillin and $100 \mu \mathrm{g} / \mathrm{ml}$ streptomycin. For treatments, exponentially growing cells were collected, counted, re-suspended in fresh culture medium and incubated in 96 sterile well plates.

\subsection{Cytotoxicity assay}

Cell viability was assessed using the MTT (3-(4,5-dimethylthiazol-2-yl)-2,5-diphenyl-2Htetrazolium bromide) assay, which is based on the ability of viable cells to metabolically reduce a yellow tetrazolium salt (MTT; Sigma) to purple crystals of formazan (Mosmann, 1983). This reaction takes place when mitochondrial reductases are active. Cells were grown in 96 -well plates $\left(5 \times 10^{5}\right.$ cells/well $)$ and incubated at $37^{\circ} \mathrm{C}$ for 72 hours with the extracts of the red sweet pepper seed and pulp obtained by different extraction methods at concentrations of $0,0.001,0.01,0.1,1,5,10,15,25$ and $100 \mu \mathrm{g} / \mathrm{ml}$, respectively, in a humidified atmosphere with $5 \% \mathrm{CO}_{2}$. The lyophilized extracts were diluted in water and extracts obtained by maceration and Soxhlet were diluted in DMSO. The final concentration of the DMSO in culture medium was always lower than $1 \%$, a concentration that has neither cytotoxic effect nor causes any interference with the colorimetric detection methods). After incubation, the medium was removed and the cells were treated with $100 \mu \mathrm{L}$ MTT for 3 hours at $37^{\circ} \mathrm{C}$. Subsequently, $100 \mu \mathrm{L}$ DMSO was added to the mixture. The solubilized formazan product was quantified with the help of a microplate reader TECAN-Sunrise ${ }^{\mathrm{TM}}$ at $570 \mathrm{~nm}$ (Tecan Group LTD, Männedorf, Switzerland). Taxol (Bristol-Myers Squibb, USA) was used as a positive control in the assay.

\subsection{Selectivity index for cytotoxicity assay in tumoral cells}

The selectivity index (SI) was calculated as the $\mathrm{IC}_{50}$ (control cells)/ $\mathrm{IC}_{50}$ (tumor cells line) ratio. A selectivity index $>1$ indicated that 
the cytotoxicity on tumor cells surpassed that on healthy non-tumor cells (Callacondo-Riva, Quispe-Mauricio, Lindo-Gamarra, \& Vaisberg, 2008).

\subsection{Determination of antioxidant properties}

The radical scavenging activity of red sweet pepper extracts was performed by the method described by Celep, Aydin, and Yesilada (2012). Each extract $(0.2 \mathrm{ml})$ was mixed with 2.8 $\mathrm{ml}$ of freshly prepared $0.06 \mathrm{mM}$ 1,1-diphenyl2-picrylhydrazyl (DPPH, Sigma-Aldrish, St. Louis, USA) solution in methanol. The mixture was shaken with a vortex mixer and incubated in the dark for $30 \mathrm{~min}$ at room temperature. The absorbance was measured at $517 \mathrm{~nm}$ (just after added the extract and after $30 \mathrm{~min}$. of dark incubation). Ascorbic acid $(176 \mu \mathrm{g} / \mathrm{ml})$ was used as reference substance (control). The absorbance was measured at $517 \mathrm{~nm}$. DPPH radical-scavenging activity was calculated as follows:

$$
\begin{aligned}
& \text { DPPH radical - scavenging activity }(\%)= \\
& \frac{A b s_{\text {control }}-A b s_{\text {Sample }}}{A b s_{\text {control }}} \times 100
\end{aligned}
$$

Where, Abscontrol, is the absorbance value of the Ascorbic acid, and Abssample, is the absorbance of the extract solution.

\section{Microbial strains and culture conditions}

Strains of Salmonella enterica ser. Enteritidis (CVCM 497), Staphylococcus aureus (CVCM 456) and Listeria monocytogenes (CVCM 449) were supplied by the "Centro Venezolano de Colecciones de Microorganismos (CVCM)" of the Institute of Experimental Biology of the University Central of Venezuela, Caracas-Venezuela for evaluating the antimicrobial activity of red sweet pepper (C. annuum L.) seed and pulp extracts against these pathogens. Strains of Salmonella enterica ser. Enteritidis and Staphylococcus aureus were individually grown in $50 \mathrm{ml}$ of tryptone soy broth (TSB) (Himedia, Mumbai, India), whereas the strain of Listeria monocytogenes was grown in $50 \mathrm{ml}$ of TSB plus yeast extract (Himedia) at $0.6 \%$. All cultures were incubated at $37^{\circ} \mathrm{C}$ for $24 \mathrm{~h}$ without agitation to obtain cells in early stationary growth phase. These conditions were obtained from growth curves previously made in the Laboratory (data not shown). The maximum population reached by the microorganisms in the growth medium was approximately $10^{8}$ Colony Forming Units $(\mathrm{CFU}) / \mathrm{ml}$.

\section{Antimicrobial activity by disc diffusion method}

The method used in this experiment was the suggested by Kirby-Bauer (Davidson \& Parish, 1989). Sterile filter-paper discs (Whatmann $\mathrm{N}^{\circ} 1$ ) measuring $9 \mathrm{~mm}$ in diameter were dipped in solutions containing aqueous or alcoholic extracts from red sweet pepper seed and pulp individually prepared at different concentrations $(0.0$; $0.1 ; 0.3 ; 0.5 \% \mathrm{v} / \mathrm{v})$. Agar disc diffusion method was used for screening of antimicrobial activity of each extract against Salmonella enterica ser. Enteritidis, Staphylococcus aureus and Listeria monocytogenes. The discs impregnated with extracts were put on Müller-Hinton agar (Himedia, Mumbai, India) plates previously inoculated with each pathogenic microorganism at $10^{8} \mathrm{CFU} / \mathrm{ml}$, and them incubated at $37^{\circ} \mathrm{C}$ for 24-48 h. The size of inhibition zone diameters surrounding filter paper disc was measured using a vernier caliper (Hauptner, Solingen, Germany). Each extract was assayed on two occasions and in duplicate $(\mathrm{n}=4)$. Sterile distilled water was used as negative control.

\section{$2.9 \quad$ Statistical analysis}

All experiments of cytotoxicity were performed at least three times. The values of $\mathrm{IC}_{50}$ of natural products were determined by a non-linear regression of individual experiments using the program GraphPad Prism v.5.02 (GraphPad Software, San Diego, CA, USA). Analysis of variance (ANOVA) in the antimicrobial and antioxidant activity of aqueous and alcoholic extracts of Red sweet pepper seed and pulp were carried out to detected differences statistically significant $(\mathrm{p}<$ 0.05 ) among their concentrations, using statistic

IJFS | October 2017 | Volume 6 | pages 222-231 
package Statgraphics Centurion XVI (StatPoint Technologies). Multiple range tests, using the Fisher's LSD method, were then applied to determine which extracts and concentrations of each extract were significantly $(\mathrm{p}<0.05)$ different.

\section{Results and Discussion}

\subsection{Cytotoxic properties on human tumoral cells}

Results demonstrated that SDP had a significant $(\mathrm{P}<0.05)$ in-vitro effect on human tumoral cell lines HeLa $\left(\mathrm{IC}_{50} 1.9 \pm 1.4\right)$ and PC3 $\left(\mathrm{IC}_{50}<1\right)$ with a moderated impact on control cells (fibroblasts) $\left(\mathrm{IC}_{50} 26.1 \pm 1.2\right)$; whereas, SFP had significant $(\mathrm{p}<0.05)$ effect over MCF-7 cell line $\left(\mathrm{IC}_{50}\right.$ $2.1 \pm 1.2)$ with a moderated impact on control cells (fibroblasts) $\left(\mathrm{IC}_{50} 25.9 \pm 1.0\right)$. A moderated cytotoxic effect on MCF-7 cell line was also observed with MFP ( $\left.\mathrm{IC}_{50} 6.8 \pm 1.1\right)$ and LFP $\left(\mathrm{IC}_{50} 5.4 \pm 1.0\right)$. On the other hand, LSd extract showed a slight cytotoxic activity on PC3 $\left(\mathrm{IC}_{50} 3.2 \pm 1.3\right)$ and HeLa $\left(\mathrm{IC}_{50} 8.9 \pm 1.1\right)$ cell lines without activity on fibroblasts, whereas SSd only showed effect on PC3 $\left(\mathrm{IC}_{50} 8.8 \pm 1.0\right)$ line (Table 1). There are few studies in the literature reporting the cytotoxic activity of red sweet pepper (C. annuum L.). In this sense, Motohashi et al. (2003) have reported similar results, indicating that hexane, acetone and methanol extracts of $C$. annuum var. angulosum, Anastasia Red showed relatively higher cytotoxic activity against two human oral tumoral cell lines (HSC2 and HSG) than against normal human gingival fibroblast (HGF), suggesting a tumor-specific cytotoxic activity.

The results showed that SDP and SFP extract had a highly selective cytotoxic action on HeLa and PC3, and MCF-7, respectively, because their Selectivity Index (SI) values were higher than 1.0 (Table 2).

\section{Antioxidant properties}

The free radical scavenging potential of both seed and pulp extracts from red sweet pepper (C. annuum L.) was determined In vitro through the DPPH method just after adding the sample and after 30 min. Both extracts (pulp and seed) showed a higher antioxidant activity at $30 \mathrm{~min}$ than at $0 \mathrm{~min}$ (Table 3$)$. MFP $(80.3 \% \pm 0.2)$ and SFP $(75.5 \% \pm 0.5)$ showed antioxidant properties significantly higher $(\mathrm{p}<0.05)$ than the rest of the extracts $(34.2 \% \pm 0.1$ to $56.5 \% \pm 0.2)$, the order of antioxidant activity of the different evaluated extracts being MFP $>\mathrm{SFP}>\mathrm{MSd}$ $>$ LSd $>$ SSd $>$ LFP $>$ SDP. A higher free radical scavenging activity for red sweet pepper $(C$. annuum L.) methanolic extracts (95\% approximately) was reported by Yazdizadeh Shotorban et al. (2012), who indicated that processing techniques involving extraction solvent, $\mathrm{pH}$, light, and heat can markedly influence the levels and efficacy of bioactive compounds of dietary supplements such as polyphenolic compounds. Ciulu-Costinescu et al. (2015) also reported a high antioxidant activity for alcoholic extracts of C. annuum L., containing $505.207 \mathrm{mg} / \mathrm{L}$ of polyphenols expressed as gallic acid equivalents and $235.884 \mathrm{mg} / \mathrm{L}$ of flavonoids expressed as quercitin equivalents.

Sweet peppers (C. annuum L.) are known as an excellent source of vitamins $\mathrm{A}$ and $\mathrm{C}$ as well as flavonoids and phenolic compounds, which are important antioxidant components that may reduce the risk of diseases (Nazzaro et al., 2009; Yazdizadeh Shotorban et al., 2012). Antioxidants are powerful substances naturally present in vegetables and fruits that can neutralize free radicals before they damage the body's cells (Oboh \& Rocha, 2007; Watjen, Chovolou, Kampkötter, \& Kahl, 2007). The antiradical activity of flavonoids and phenolics is principally based on the redox properties of their hydroxy groups and the structural relationships between different parts of their chemical structure (Materska \& Perucka, 2005).

\subsection{Antimicrobial properties}

Lyophilized extracts of red sweet pepper (C. annuum L.) pulp and seed did not show antimicrobial properties against L. monocytogenes, $S$. enterica ser. Enteritidis and $S$. aureus. In contrast, both pulp and seed alcoholic extracts obtained by maceration and Soxhlet extraction showed slight antimicrobial properties (Inhibi- 
Table 1: Cytotoxic properties of Red sweet pepper (Capsicum annuum L.) pulp and seed extracts on various human tumor cell lines

\begin{tabular}{cccccc}
\hline \multirow{2}{*}{ Extracts /Cell line } & \multicolumn{5}{c}{ IC $_{50}(\mu \mathbf{g} / \mathbf{m L})^{a}$} \\
\cline { 2 - 6 } & PC3 & HeLa & MCF-7 & SKBr3 & Fibroblasts \\
\hline MFP & $>100$ & $>100$ & $6.8 \pm 1.1$ & WA & $38.9 \pm 1.3$ \\
LFP & WA & WA & $5.4 \pm 1.0$ & WA & $20.5 \pm 1.0$ \\
SFP & WA & $>100$ & $2.1 \pm 1.2$ & $37.7 \pm 1.1$ & $25.9 \pm 1.0$ \\
SDP & $<1$ & $1.9 \pm 1.4$ & WA & $33.7 \pm 1.0$ & $26.1 \pm 1.2$ \\
MSd & $<1$ & $46.5 \pm 1.0$ & WA & WA & WA \\
LSd & $3.2 \pm 1.3$ & $8.9 \pm 1.1$ & WA & $32.5 \pm 1.0$ & WA \\
SSd & $8.8 \pm 1.0$ & $>100$ & WA & WA & WA \\
Taxol & $0.003 \pm 1.1$ & $0.1 \pm 1.1$ & $0.06 \pm 1.3$ & $1.0 \pm 1.2$ & $0.8 \pm 1.2$ \\
\hline
\end{tabular}

$a$ Values represent the mean of three (3) determinations \pm standard deviation. IC $_{50}$ : inhibitory concentration $50 \%$; MFP: Sweet pepper fresh pulp extract obtained by maceration. LFP: Sweet pepper fresh pulp extract obtained by lyophilization. SFP: Sweet pepper fresh pulp extract obtained by Soxleth equipment. SDP: Sweet pepper dried pulp extract obtained by Soxleth equipment. MSd: Sweet pepper seed extract obtained by maceration. LSd: Sweet pepper seed extract obtained by lyophilization. SSd Sweet pepper seed extract obtained by Soxleth equipment. Taxol: chemical compound used as control. WA: without activity. HeLa (human cervix carcinoma); PC3 (human prostate carcinoma); MCF-7 (breast carcinoma, without over-expression of the HER2/c-erb-2 gene); SKBr3 (breast carcinoma, in which the HER2/c-erb-2 gene is over-expressed); Fibroblasts (healthy cells of human connective tissue, used as control)

Table 2: Values of selectivity index (SI) of the Red sweet pepper (Capsicum annuum L.) seed and pulp extracts

\begin{tabular}{ccccc}
\hline \multirow{2}{*}{ Extracts / Cell line } & \multicolumn{4}{c}{ Selectivity Index $(\text { SI })^{a}$} \\
\cline { 2 - 5 } & PC3 & HeLa & MCF-7 & SKBr 3 \\
\hline MFP & 0.4 & 0.4 & 5.7 & - \\
LFP & - & - & 3.8 & - \\
SFP & - & 0.3 & 12.1 & 0.7 \\
SDP & 5.2 & 13.9 & - & 0.8 \\
MSd & - & - & - & - \\
LSd & - & - & - & - \\
SSd & - & - & - & - \\
Taxol & 250 & 6 & 13 & 0.8 \\
\hline
\end{tabular}

$a$ Values represent the mean of three (3) determinations. MFP: Sweet pepper fresh pulp extract obtained by maceration. LFP: Sweet pepper fresh pulp extract obtained by lyophilization. SFP: Sweet pepper fresh pulp extract obtained by Soxleth equipment. SDP: Sweet pepper fried pulp extract obtained by lyophilization. SFP: Sweet pepper fresh pulp extract obtained by Soxleth equipment. SDP: Sweet pepper obtained by lyophilization. SSd Sweet pepper seed extract obtained by Soxleth equipment. Taxol: chemical compound used as control. WA: without activity. HeLa (human cervix carcinoma); PC3 (human prostate carcinoma); MCF-7 (breast carcinoma, without over-expression of without activity. HeLa (human cervix carcinoma); PC3 (human prostate carcinoma); MCF-7 (breast carc
the HER2/c-erb-2 gene); SKBr3 (breast carcinoma, in which the HER2/c-erb-2 gene is over-expressed). 
Table 3: Antioxidant properties of Red sweet pepper (Capsicum annuum L.) pulp and seed extracts

\begin{tabular}{ccc}
\hline \multirow{2}{*}{ Extract } & \multicolumn{2}{c}{ Percentage $(\mathbf{\%} ; \mathbf{v} / \mathbf{v})^{a}$} \\
\cline { 2 - 3 } & $\mathbf{T}=\mathbf{0}$ min. & $\mathbf{T}=\mathbf{3 0}$ min. \\
\hline MFP & $77.0 \pm 0.2 \mathrm{Aa}$ & $80.3 \pm 0.2 \mathrm{Ba}$ \\
LFP & $33.6 \pm 0.4 \mathrm{Ab}$ & $45.2 \pm 0.2 \mathrm{Bb}$ \\
SFP & $73.4 \pm 0.2 \mathrm{Ac}$ & $75.5 \pm 0.5 \mathrm{Bc}$ \\
SDP & $27.4 \pm 0.3 \mathrm{Ad}$ & $34.2 \pm 0.1 \mathrm{Bd}$ \\
MSd & $40.4 \pm 0.8 \mathrm{Ae}$ & $56.5 \pm 0.2 \mathrm{Be}$ \\
LSd & $31.3 \pm 0.3 \mathrm{Af}$ & $51.9 \pm 0.2 \mathrm{Bf}$ \\
SSd & $34.4 \pm 0.5 \mathrm{Ag}$ & $51.6 \pm 0.1 \mathrm{Bf}$ \\
\hline
\end{tabular}

$a$ Values represent the mean of three determination \pm Standard deviation. Different capital letters (A, B) indicate significant differences $(\mathrm{p}<0.05)$ between analysis time $(0 \mathrm{~min}$ or $30 \mathrm{~min}$.), whereas different lowercase letters $(\mathrm{a}, \mathrm{b}, \mathrm{c}, \mathrm{d}, \mathrm{e}, \mathrm{f}, \mathrm{g})$ indicate significant differences $(\mathrm{p}<0.05)$ between extracts. MFP: Sweet pepper fresh pulp extract obtained by maceration. LFP: Sweet pepper fresh pulp extract obtained by lyophilization. SFP: Sweet pepper fresh pulp extract obtained by Soxleth equipment. SDP: Sweet pepper dried pulp extract obtained by Soxleth equipment. MSd: Sweet pepper seed extract obtained by maceration. LSd: Sweet pepper seed extract obtained by lyophilization. SSd Sweet pepper seed extract obtained by Soxleth equipment.

Table 4: Antimicrobial properties of Red sweet pepper (Capsicum annuum L.) pulp and seed alcoholic extracts against L. monocytogenes. S. Enteritidis. and S. aureus

\begin{tabular}{ccccc}
\hline Vegetable material & \multicolumn{4}{c}{ Inhibition zone $(\mathbf{m m}) \mathbf{A}$} \\
\hline Alcoholic extract & Concentration (\%) & L. monocytogenes & S. Enteritidis & S. aureus \\
\hline \multirow{4}{*}{ MFP } & 0.00 & $0.30 \pm 0.00 \mathrm{Aa}$ & $0.30 \pm 0.00 \mathrm{Aa}$ & $0.30 \pm 0.00 \mathrm{Aa}$ \\
& 0.10 & $0.35 \pm 0.07 \mathrm{Aa}$ & $0.30 \pm 0.00 \mathrm{Aa}$ & $0.30 \pm 0.00 \mathrm{Aa}$ \\
& 0.30 & $0.40 \pm 0.00 \mathrm{Aa}$ & $0.35 \pm 0.07 \mathrm{Aa}$ & $0.30 \pm 0.00 \mathrm{Aa}$ \\
& 0.50 & $0.40 \pm 0.00 \mathrm{Aa}$ & $0.35 \pm 0.07 \mathrm{Aa}$ & $0.40 \pm 0.00 \mathrm{Ab}$ \\
\hline \multirow{5}{*}{ SFP } & 0.00 & $0.20 \pm 0.00 \mathrm{Ba}$ & $0.20 \pm 0.00 \mathrm{Aa}$ & $0.20 \pm 0.00 \mathrm{Aba}$ \\
& 0.10 & $0.20 \pm 0.00 \mathrm{Ba}$ & $0.20 \pm 0.00 \mathrm{Aa}$ & $0.25 \pm 0.00 \mathrm{Aba}$ \\
& 0.30 & $0.20 \pm 0.00 \mathrm{Ba}$ & $0.25 \pm 0.07 \mathrm{Aa}$ & $0.35 \pm 0.00 \mathrm{Aba}$ \\
& 0.50 & $0.20 \pm 0.00 \mathrm{Ba}$ & $0.35 \pm 0.07 \mathrm{Aa}$ & $0.40 \pm 0.00 \mathrm{Aba}$ \\
\hline \multirow{5}{*}{ SDP } & 0.00 & $0.20 \pm 0.00 \mathrm{Ba}$ & $0.20 \pm 0.00 \mathrm{Aa}$ & $0.15 \pm 0.00 \mathrm{Ca}$ \\
& 0.10 & $0.20 \pm 0.00 \mathrm{Ba}$ & $0.25 \pm 0.07 \mathrm{Aa}$ & $0.25 \pm 0.00 \mathrm{Ca}$ \\
& 0.30 & $0.30 \pm 0.00 \mathrm{Bb}$ & $0.35 \pm 0.07 \mathrm{Aa}$ & $0.20 \pm 0.00 \mathrm{Ca}$ \\
MSd & 0.50 & $0.35 \pm 0.07 \mathrm{Bb}$ & $0.35 \pm 0.07 \mathrm{Aa}$ & $0.25 \pm 0.00 \mathrm{Ca}$ \\
\hline & 0.00 & $0.25 \pm 0.07 \mathrm{Aa}$ & $0.20 \pm 0.07 \mathrm{Aa}$ & $0.15 \pm 0.07 \mathrm{BCa}$ \\
& 0.10 & $0.30 \pm 0.00 \mathrm{Aa}$ & $0.25 \pm 0.00 \mathrm{Aa}$ & $0.20 \pm 0.00 \mathrm{BCa}$ \\
& 0.30 & $0.40 \pm 0.14 \mathrm{Aa}$ & $0.30 \pm 0.14 \mathrm{Aa}$ & $0.25 \pm 0.07 \mathrm{BCa}$ \\
SSd & 0.50 & $0.50 \pm 0.14 \mathrm{Aa}$ & $0.40 \pm 0.00 \mathrm{Aa}$ & $0.35 \pm 0.07 \mathrm{BCa}$ \\
\hline & 0.00 & $0.15 \pm 0.07 \mathrm{Ba}$ & $0.15 \pm 0.07 \mathrm{Aa}$ & $0.30 \pm 0.00 \mathrm{Ada}$ \\
& 0.10 & $0.20 \pm 0.00 \mathrm{Ba}$ & $0.35 \pm 0.07 \mathrm{Aa}$ & $0.35 \pm 0.00 \mathrm{Ada}$ \\
& 0.30 & $0.20 \pm 0.00 \mathrm{Ba}$ & $0.30 \pm 0.14 \mathrm{Aa}$ & $0.45 \pm 0.00 \mathrm{Ada}$ \\
& 0.50 & $0.25 \pm 0.07 \mathrm{Ba}$ & $0.35 \pm 0.07 \mathrm{Aa}$ & $0.45 \pm 0.00 \mathrm{Ada}$ \\
\hline
\end{tabular}

${ }^{a}$ Values are mean of two determinations \pm standard deviation realized by duplicate $(\mathrm{n}=4)$. Different lowercase (a, b) in the same column represent pepper fresh pulp extract obtained by maceration. SFP: Sweet pepper fresh pulp extract obtained by Soxleth equipment. SDP: Sweet pepper pepper fresh pulp extract obtained by maceration. SFP: Sweet pepper fresh pulp extract obtained by Soxleth equipment. SDP: Sweet pepper dried pulp extract obtained by Soxleth equipment. MSd: Sweet pepper seed extract obtained by maceration. SSd Sweet pepper seed extract
obtained by Soxleth equipment. Different capital letters $(A, B)$ in the same column represent significant statistically differences $(p<0.05)$ among extracts for each microorganism. 
tion halos range between 0.15 a $0.50 \mathrm{~mm}$ ) against those microorganisms, which increased slight with increasing extract concentration in some cases (Table 4). Statistically significant differences $(p<0.05)$ among extracts were detected; however, statistically significant differences were not found ( $\mathrm{p}>0.05$ ) among the different concentrations evaluated for each type of extract. Higher antimicrobial activity was reported by Nazzaro et al. (2009) against other microorganisms such as $B$. cereus and $E$. coli, showing inhibition halos of $15 \mathrm{~mm}$ and $7 \mathrm{~mm}$ for alcoholic extracts of two varieties of sweet pepper $C$. annuum L. against B. cereus (DSM4313 and DSM 4384) and halos of $7 \mathrm{~mm}$ for $E$. coli EC 101 . Antifungal activity against $P$. expansum DSM 6694 ( $8 \mathrm{~mm}$ ) and D. hansenii DSM $70238(16 \mathrm{~mm})$ was also reported by these authors. Ciulu-Costinescu et al. (2015) also reported a bactericidal effect of $C$. annuum L. alcoholic extracts against Staphylococcus aureus, Pseudomonas aeruginosa, E. coli, Enterococcus faecalis and B. subtilis. Whereas, Diz et al. (2006) found fungicidal activity from protein fractions obtained from C. annuum $\mathrm{L}$. (Chilli peppers) against Candida albicans, Saccharomyces cerevisiae and Schizosaccharomyces pombe, the authors indicating that one of the fractions also promoted several morphological changes to $C$. albicans, including the formation of pseudohyphae, as revealed by scanning electron micrography. In contrast to all those results, Motohashi et al. (2003) did not find any antibacterial activity of Anastasia Red, C. annuum L. sweet pepper extracts (hexane, acetone and methanol) against Helicobacter pylori.

The differences found between our results and others authors could have been due to $C$. annuum L. variety used in each study. In this sense, Padilha et al. (2015) found a great variability in the bioactive compounds present and their concentrations in different varieties of $C$. annuum peppers. Some of these compounds such as polyphenols and other antioxidants can affect the growth and metabolism of fungi, insects and bacteria (Alberto, Canavosio, \& de Nadra, 2006; Padilha et al., 2015). Similarly, Davidson and Taylor (2007) reported that polyphenols act on cytoplasm membranes causing leakage cell as well as on the membrane proteins such as ATPase. In the same way, there are other compounds presents in Capsicum peppers that have antimicrobial activity such as capsaicinoids (Omolo et al., 2014; Akhtar et al., 2017), which are compounds whose concentrations vary significantly among varieties of pepper. Capsaicinoids are compounds naturally present in pungent peppers, being the capsaicin the most widely studied. Sweet pepper does not contain capsaicin; however, it has capsinoids such as nordihydrocapsiate (Kobata et al., 1999), which is a compound with a similar structure to capsaicinoids, which present an ester group instead of amide group. The slight antimicrobial properties detected in the present research for the methanolic extracts of red sweet pepper could be due to polyphenols, other antioxidants and nordihydrocapsiate. However it is necessary to carry out future studies to confirm this fact because there is little research work cited in the literature with respect to sweet pepper.

\section{Conclusions}

The use of phytochemicals present in fruits and vegetable has gained worldwide acceptance as a novel source of chemopreventive agents against cancer cells, because the non-nutrient phytochemicals have showed that can either block or reverse multistage carcinogenesis. The results of this research showed the strong cytotoxic and antioxidant effects that some red sweet pepper $(C$. annuum L.) extracts could have. Tumoral cell lines from HeLa, MCF-7 and PC3 were more sensitive to red sweet pepper $(C$. annuum $\mathrm{L}$.) extracts than SKBr3. Alcoholic extracts of fresh pulp obtained by maceration and Soxhlet equipment showed the higher antioxidant activity in comparison with the rest of extracts. The alcoholic extracts showed only slight antimicrobial properties. These findings demonstrated the potential of red sweet pepper as a source of antioxidant and cytotoxic compounds, and suggest the need for further studies to determine which compounds impart these properties to this fruit and which molecular mechanisms are associated with its antitumoral activity. 


\section{Acknowledgements}

This study was supported by the FONACIT (Fondo Nacional de Ciencia, Tecnología e Innovación) of Ministry of the Popular Power for the Science, Technology and Intermediate Industries of the Bolivarian Government of Venezuela through the Project PEI N²012000823.

\section{References}

Akhtar, F., Sharif, H. M., Mallick, M. A., Zahoor, F., Abdulmalik, A., Baig, W., ... Ramzan, R. (2017). Capsaicin: its biological activities and in silico target fishing. Acta Poloniae Pharmaceutica-Drug Research, 74 (2), 321-329. Retrieved from http : / / www . ptfarm.pl/pub/File/Acta_Poloniae/2017/ Nr\%5C\%202/321.pdf

Alberto, M. R., Canavosio, M. A. R., \& de Nadra, M. C. M. (2006). Antimicrobial effect of polyphenols from apple skins on human bacterial pathogens. Electronic Journal of Biotechnology, 9(3), 205-209. doi:10.2225/ vol9-issue3-fulltext-1

Ayala-Zavala, J. F., Vega-Vega, V., RosasDominguez, C., Palafox-Carlos, H., VillaRodriguez, J. A., Siddiqui, M. W., ... Gonzalez-Aguilar, G. A. (2011). Agroindustrial potential of exotic fruit byproducts as a source of food additives. Food Research International, 44(7, SI), 1866-1874. doi:10.1016/j.foodres.2011.02.021

Callacondo-Riva, D., Quispe-Mauricio, A., Lindo-Gamarra, S., \& Vaisberg, A. J. (2008). Cytotoxic activity of ethanolic extract of Gnaphalium spicatum keto keto on human tumor cell lines. Revista Peruana de Medicina Experimental y Salud Publica, 25(4), 380-385. Retrieved from http: / / www . scielo. org . pe / scielo . php ? script $=$ sci_arttext $\&$ pid $=$ S1726 46342008000400006\&nrm=iso

Celep, E., Aydin, A., \& Yesilada, E. (2012). A comparative study on the in vitro antioxidant potentials of three edible fruits: cornelian cherry, japanese persimmon and cherry laurel. Food and Chemical Toxicol- ogy, 50(9), 3329-3335. doi:10.1016/j.fct. 2012.06.010

Chavez, K., Compagnone, R. S., Riina, R., Briceno, A., Gonzalez, T., Squitieri, E., ... Suarez, A. I. (2013). Natural product communications. (Chap. Crotofolane Diterpenoids from Croton caracasanus, Vol. 8, 12, pp. 1679-1682). Retrieved from http: //www.naturalproduct.us/content/npc-812-2013.pdf

Ciulu-Costinescu, F., Chifiriuc, M. C., Popa, M., Bleotu, C., Neamtu, J., Averis, L. M. E., ... Belu, I. (2015). Screening of polyphenol content and in vitro studies of antioxidant, antibacterial and cytotoxic activities of Capsicum Annuum extracts. Revista De Chimie, 66(9), 1261-1266.

Davidson, P. M. \& Parish, M. E. (1989). Methods for testing the efficacy of food antimicrobials. Food Technology, 43(1), 148-155.

Davidson, P. M. \& Taylor, T. M. (2007). Chemical preservatives and natural antimicrobial compounds. In Food microbiology: fundamentals and frontiers, third edition (pp. 713-745). American Society of Microbiology. Retrieved from http://www . asmscience. org / content / book / 10 . 1128/ 9781555815912.ch33

Diz, M. S. S., Carvalho, A. O., Rodrigues, R., Neves-Ferreira, A. G. C., Da Cunha, M., Alves, E. W., ... Gomes, V. M. (2006). Antimicrobial peptides from chilli pepper seeds causes yeast plasma membrane permeabilization and inhibits the acidification of the medium by yeast cells. Biochimica Et Biophysica Acta-general Subjects, $1760(9)$, 1323-1332. doi:10.1016/j.bbagen.2006.04. 010

Gonzalez-Aguilar, G., Robles-Sanchez, R. M., Martinez-Tellez, M. A., Olivas, G. I., Alvarez-Parrilla, E., \& De La Rosa, L. A. (2008). Bioactive compounds in fruits: health benefits and effect of storage conditions. Stewart Postharvest Review, 4(3), $1-10$.

Hernandez-Ortega, M., Ortiz-Moreno, A., Hernandez-Navarro, M. D., ChamorroCevallos, G., Dorantes-Alvarez, L., \& Necoechea-Mondragon, H. (2012). Antioxidant, antinociceptive, and anti- 
Cytotoxic, antioxidant and antimicrobial properties of red sweet pepper $\quad 231$

inflammatory effects of carotenoids extracted from dried pepper (Capsicum annuum 1.) Journal of Biomedicine and Biotechnology, 2012, 1-10. doi:10.1155/ 2012/524019

Kobata, K., Sutoh, K., Todo, T., Yazawa, S., Iwai, K., \& Watanabe, T. (1999). Nordihydrocapsiate, a new capsinoid from the fruits of a nonpungent pepper, Capsicum annuum. Journal of Natural Products, 62(2), 335-336. doi:10.1021/np9803373

Leong, K. L., Alviarez, P. F., Compagnone, R. S., \& Suarez, A. I. (2009). Isolation and structural elucidation of chemical constituents of Amanoa almerindae. Pharmaceutical Biology, 47(6), 496-499. doi:10 . 1080/13880200902838717

Materska, M. \& Perucka, I. (2005). Antioxidant activity of the main phenolic compounds isolated from hot pepper fruit (Capsicum annuuml.) Journal of Agricultural and Food Chemistry, 53(5), 17501756. doi:10.1021/jf035331k

Mosmann, T. (1983). Rapid colorimetric assay for cellular growth and survival: application to proliferation and cytotoxicity assays. Journal of Immunological Methods, 65(1), 55-63. doi:10.1016/0022-1759(83) 90303-4

Motohashi, N., Wakabayashi, H., Kurihara, T., Takada, Y., Maruyama, S., Sakagami, H., ... Molnar, J. (2003). Cytotoxic and multidrug resistance reversal activity of a vegetable, 'anastasia red', a variety of sweet pepper. Phytotherapy Research, 17(4), 348-352. doi:10.1002/ptr.1144

Nazzaro, F., Caliendo, G., Arnesi, G., Veronesi, A., Sarzi, P., \& Fratianni, F. (2009). Comparative content of some bioactive compounds in two varieties of Capsicum annuum l. sweet pepper and evaluation of their antimicrobial and mutagenic activities. Journal of Food Biochemistry, 33(6), 852-868. doi:10.1111/j. 1745-4514.2009. 00259.x

Oboh, G. \& Rocha, J. B. (2007). Leading edge, antioxidants research. In H. V. Panglossi (Ed.), (Chap. Antioxidants in food: A new challenge for food processors, pp. 35-64). New York: Nova Science Publishers, Inc.
Oboh, G. \& Rocha, J. B. T. (2008). Hot pepper (Capsicum spp.) protects brain from sodium nitroprusside- and quinolinic acidinduced oxidative stress in vitro. Journal of Medicinal Food, 11(2), 349-355. doi:10. 1089/jmf.2007.341

Omolo, M. A., Wong, Z.-Z., Mergen, K., Hastings, J. C., Le, N. C., Reil, H. A., ... Baumler, D. J. (2014). Antimicrobial properties of chili peppers. Journal of Infectious Diseases and Therapy, 2(4), 145. doi:10.4172/ 2332-0877.1000145

Padilha, H. K. M., Pereira, E. D. S., Munhoz, P. C., Vizzotto, M., Valgas, R. A., \& Barbieri, R. L. (2015). Genetic variability for synthesis of bioactive compounds in peppers (Capsicum annuum) from brazil. Food Science and Technology (Campinas), 35(3), 516-523. doi:10.1590/1678-457x. 6740

Shaha, R. K., Rahman, S., \& Asrul, A. (2013). Bioactive compounds in chilli peppers (Capsicum annuum 1.) at various ripening (green, yellow and red) stages. Annals of Biological Research, 4 (8), 27-34. Retrieved from http://www.scholarsresearchlibrary. com / abstract / bioactive - compounds - in chilli - peppers - capsicum - annuum - 1 - at various - ripening - green - yellow - and - red stages-7125.html

Suarez, A. I., Blanco, Z., Compagnone, R. S., Salazar-Bookaman, M. M., Zapata, V., \& Alvarado, C. (2006). Anti-inflammatory activity of Croton cuneatus aqueous extract. Journal of Ethnopharmacology, 105(1-2), 99-101. doi:10.1016/j.jep.2005.10.006

Watjen, W., Chovolou, Y., Kampkötter, A., \& Kahl, R. (2007). Leading edge, antioxidants research. In H. V. Panglossi (Ed.), (Chap. Anti and Prooxidative effects of flavonoids, pp. 1-16). New York: Nova Science Publishers, Inc.

Yazdizadeh Shotorban, N. I., Jamei, R., \& Heidari, R. (2012). Antioxidant activities of two sweet pepper Capsicum annuum 1. varieties phenolic extracts and the effects of thermal treatment. Avicenna Journal of Phytomedicine, 3(1), 25-34. doi:10.22038/ ajp. 2012.8 